\title{
Remedy for British science
}

SIR-I agree with the spirit of your leading article (Nature 323, 655: 1986) bemoaning the plight of British science, but I would question the political utility of the "precepts' you urge the Advisory Board for the Research Councils (ABRC) to adopt to promote its case. In many ways they are all too familiar claims that those defending science have used in its defence. As such, they are as likely to be as unsuccessful in persuading Whitehall that its 'policies' if that is not to dignify the disjointed initiatives of recent years too much - are damaging science as has been the more straightforward claim that 'we need more money'.

In many ways your precepts understate the real damage that is being done to the infrastructure of British science research. ABRC would be better advised, I believe, to make more of the wider national economic context in which science research and development finds itself, as well as to draw on what detailed information there is about the real damage that is being done to science at 'grass-roots level', the fundamental knowledge-generating culture of science.

On the first point, ABRC would do well to point out to its political masters that, according to the government's own Central Statistical Office, British industry, excluding oil, grew by only 1.5 per cent in 1979-85: little wonder that industry has had to look 'innovatory gift-horses in the

\section{Pressure to publish}

SIR-Writing in your New Journals Review issue, Mary Holmes admirably summed up the problems we face with the ever-increasing range of specialized scientific periodicals available (Nature 323, 359-360; 1986). A cause contributing to this information explosion is the extraordinary pressure on scientists to publish. This is certainly noticeable in the medical field, where appointments and promotions frequently hinge on the sheer number of papers published in reputablesounding journals. (A letter to Nature might get more brownie points than a paper in The British Journal of Controversial and Spurious Knowledge but 70 papers are more likely to get you a senior lecturership than one seminal paper.) This puts pressure on scientists to subdivide pieces of research to produce a number of papers rather than one complete publication.

The recent attempts in Britain to assess the research worth of entire departments or institutions on the strength of five publications has not proved particularly happy, but I do not see why the abilities of an individual should not be assessed on the strength of half-a-dozen papers. If mouth'. Moreover, where growth has occurred in the economy - in the financial sector - there appears to be little incentive on the part of financiers to invest in innovative research and development, basic, strategic or applied: money is best made out of money, on the financial markets.

At the more local level of laboratory life, my own research into the state of plant biotechnology and plant breeding in the United Kingdom reveals a failure by government to understand the research interests, abilities, needs and capacities for innovation of plant science. The speed and multidirectional nature of initiatives including privatization, rationalization and reorganization tend to pull (and literally so for its staff) science in opposite directions, breaking up the critical mass of research so vital to the future. Given the broader economic context sketched abo$v e$, it is unlikely that scientific research and development is moving sideways into an expanding world of commercial opportunity. Management of science does need to be improved at national and local level: but clearly it can be effective only if it is informed by and sensitive to both.

\section{Plant Biotechnology Project,}

A.J. Webster

Cambridgeshire College of Arts and

Technology,

East Road,

Cambridge CB1 1PT, UK

enough institutions changed that part on the back of their job application forms which says "Publications" to "List not more than six of your publications" the pressure on scientists would change to trying to produce a small number of very good publications. If this happened, a lot of semi-vanity publications would cease, and much material currently appearing in glossy print would be reduced to a footnote saying something like "Further details of this experiment are obtainable from the author on request" with no great loss to the flow of scientific information. Martin GuHa

Institute of Psychiatry Library,

De Crespigny Park, Denmark Hill, London SE5 $8 A F, U K$

\section{Scots elders}

SIR-In the Opinion article "British science over the hill" (Nature 323, 655; 1986), you say that three Scottish universities are more than 150 years old. The true figure is four: St Andrews (founded 1411), Glasgow (1451), Aberdeen (1495) and Edinburgh (1583).

\section{Scotforth Road,}

A.M. Hetherington

Lancaster LA1 4SD, UK

\section{Isolated South Africa}

SIR-Nature has a sound record (see 322, $115 ; 1986)$ on human rights and freedom from repression for academics, but the conditions in South Africa would probably not have persisted if the grandees of the scientific community and the other learned academic communities had deployed their corporate influence against apartheid. In general, scientists and academics enjoy great prestige and privilege, and exert considerable influence within their own institutions. A large part of scientific research is supported by the public purse, either directly from government grants or from charitable foundations. It is not difficult for scientists to retreat into their laboratories until their research grants are up for renewal.

The cause of international scholarship is not more important than the fate and dignity of some 23 million black South Africans and five million white South Africans. One characteristic feature of the South African regime is its sensitivity to isolation. So long as South African athletes, diplomats, scholars and other professional and business people are granted free access to countries outside South Africa, especially the United Kingdom, Canada and the United States, the present regime in Pretoria knows that it will rule the Cape for a very long time.

The arguments against sanctions are based on previous experience when there was no common consensus for sanctions among the major European governments, Canada and the United States. There now seems to be a growing trend towards such a consensus.

J.A. BARNES Department of Oral Biology,

University of Alberta, Edmonton, Alberta, Canada T6G $2 N 8$

\section{Titles of references}

SIR-I agree with John Maddox (Nature $322,681 ; 1986)$ that scientific literature is poorly written for the communication of the essential ideas of the research carried out.

One point he neglected to note is that a major contribution to this state is the obscure documentation of references. It is my opinion that a complete reference should always include the title of any cited work. I find this omission a great hindrance when researching related topics because I cannot determine beforehand whether an article is even remotely connected to my needs.

Unfortunately, I note that Nature's reference style omits the titles of cited articles from journals. Your editors are contributing to this lack of communication as much as the authors.

General Delivery, Yellowknife, NWT, Canada X1A $2 L 8$ 